\title{
FAULT DETECTION IN UNDERGROUND CABLES BY USING WAVELET TECHNIQUE (WT)
}

\author{
Ali Hassan Ibrahim Mansour \\ Elect. Eng. Dept., Faculty of Eng. Al-Azhar University, Qena, Egypt
}

\begin{abstract}
:
This paper describes a novel fault-detection technique of high voltage underground cables. Electric power systems have rapidly grown for the past fifty years. Speedy and precise fault location plays an important role in accelerating system restoration, reducing outage time, reducing great financial loss and significantly improving system reliability. Therefore, this paper presents a fault detection, classification and fault location estimation method based on Discrete Wavelet Transform for medium voltage $11 \mathrm{kV}$ underground cable. Different faults (Lg, LLg, and LLLg) and at different locations $2 \mathrm{~km}, 4 \mathrm{~km}$ and $6 \mathrm{~km}$ of $10 \mathrm{~km}$ length are simulated by Mat Lab, and then certain selected features of the wavelet transformed signals are used as an input. From the results, it was found that the percentage error in wavelet Transform output is very less. Hence, it can be concluded that the proposed technique is able to offer high accuracy in both of the fault classification and fault location.
\end{abstract}

\section{KEYWORDS: Cable, Discrete, Fault. Matlab, Time Arrival, Ravelling, Sampling Period, Wavelet,}

\section{INTRODUCTION}

Underground cables have been widely applied in power distribution networks due to the benefits of underground connection, involving more secure than overhead lines in bad weather, less liable to damage by storms or lightning, no susceptible to trees, less expensive for shorter distance, environment-friendly and low maintenance. However, the disadvantages of underground cables should also be mentioned, including 8 to 15 times more expensive than equivalent overhead lines, less power transfer capability, more liable to permanent damage following a flash-over, and difficult to locate fault. Faults in underground cables can be normally classified as two categories: incipient faults and permanent faults. Usually, incipient faults in power cables are gradually resulted from the aging process, where the localized deterioration in insulations exists. In several research papers, the fault classification or the phase with fault appearance can be obtained from employing trial and error method [1] or from the artificial intelligent decision algorithms [2]. However, most research works have only considered in the fault diagnosis for overhead transmission and distribution systems while research work rarely mention about the fault diagnosis in underground distribution system. The techniques to detect and determine the fault location in underground distribution system are discussed in several research papers [3] but the types of fault and the phase with fault appearance are as important as fault location. As a result, it is useful if the fault types in the underground distribution system can be identified using wavelet transform. Electrical overstress in conjunction with mechanical deficiency, unfavorable environmental condition and chemical pollution, can cause the irreparable and irreversible damages in insulations. Eventually, incipient faults would fail into permanent faults sooner or later. In this proposed work, taking into consideration of the requirement of a robust and highly efficient technique for 
fault identification and localization in high voltage underground power cable, a novel scheme has been proposed that ensures not only highly precise identification and localization accuracy but also provides an insight for it future utilization with real time power utilities. Further taking into consideration of the robustness of the wavelet transform technique [4], which has established as a robust approach for signal analysis in time as well as frequency domain, in paper Wavelet Transform (WT) approach is employed for fault detection, classification with fault current based [5] and the developed model has been tested for varied length $(2 \mathrm{~km}, 4 \mathrm{~km}$ and $6 \mathrm{~km}$ respectively) of power cables.

\section{WAVELET TRANSFORM}

A wavelet is a mathematical function used to divide a given function or continuous-time signal into different scale components. Usually one can assign a frequency range to each scale component. Each scale component can then be studied with a resolution that matches its scale. A wavelet transform is the representation of a function by wavelets. The wavelets are scaled and translated copies (known as "daughter wavelets") of a finitelength or fast-decaying oscillating waveform (known as the "mother wavelet"). Wavelet transforms have advantages over traditional Fourier transforms for representing functions that have discontinuities and sharp peaks, and for accurately deconstructing and reconstructing finite, non-periodic and/or non-stationary signals.

Wavelet transforms are classified into discrete wavelet transforms (DWTs) and continuous wavelet transforms (CWTs).In the wavelet transform we should note that both DWT and CWT are continuous-time (analog) transforms. They can be used to represent continuous-time (analog) signals. CWTs operate over every possible scale and translation whereas DWTs use a specific subset of scale and translation values or representation grid. There are a large number of wavelet transforms each suitable for different applications.

The wavelet transform can be accomplished in two different ways depending on what information is required out of this transformation process. The first method is a continuous wavelet transform (CWT), where one obtains a surface of wavelet Coefficients, CWT(b,a), for different values of scaling ' $a$ ' and translation ' $b$ ', and the second is a Discrete Wavelet Transform (DWT), where the scale and translation are discredited, but not are independent variables of the original signal. In the CWT the variables 'a' and 'b' are continuous. DWT results in a finite number of wavelet coefficients depending upon the integer number of discretization step in scale and translation, denoted by ' $m$ ' and ' $n$ '. If $a_{0}$ and $b_{0}$ are the segmentation step sizes for the scale and translation respectively, the scale and translation in terms of these parameters will be

$$
\begin{aligned}
& a=a_{0}^{m} \text { and } b=b_{0} a_{0}^{m} \\
& \Psi_{b, a}(\mathrm{t})=\frac{1}{\sqrt{a \Psi\left(\mathrm{t}-\frac{b}{a}\right)}}
\end{aligned}
$$

The above presented equation represents the mother wavelet of continuous time wavelet series. After discretization in terms of the parameters, $a_{0}, b_{0}$, 'm' and 'n', the mother wavelet can be written as,

$$
\begin{gathered}
\Psi_{b, a}(\mathrm{~m}, \mathrm{n})=\frac{1}{\sqrt{a_{0}} \Psi\left(\mathrm{t}-\frac{n b_{0} a_{0}^{m}}{a_{0}^{m}}\right)} \\
\Psi_{b, a}(\mathrm{~m}, \mathrm{n})=a_{0}^{\frac{m}{2}} \Psi\left(\mathrm{ta}_{0}^{-m}-\mathrm{nb}_{0}\right)
\end{gathered}
$$

After discretization, the wavelet domain coefficients are no longer represented by a simple 'a' and 'b'. Instead they are represented in terms of ' $m$ ' and ' $n$ '. The discrete wavelet coefficients DWT (m, n) are given by equation: 


$$
D W T(\mathrm{~m}, \mathrm{n})=\mathrm{a}_{0}^{\frac{m}{2}} \int_{-\infty}^{+\infty} f(\mathrm{t}) \Psi\left(\mathrm{ta}_{0}^{-m}-\mathrm{nb}_{0}\right) \mathrm{dt}
$$

The transformation is over continuous time but the wavelets are the transformation is over continuous time but the wavelets are represented in a discrete fashion. Like the CWT, these discrete wavelet coefficients represent the correlation between the original signal and wavelet for different combinations of ' $m$ ' and ' $n$ '. In this study, the line current signals are used as the input signals of the wavelet analysis. The DWT, using a Daubechies-4 wavelet (db4), performed better at identifying the start and end of a disturbance [1-4]. The Daubechies wavelet is very well suited for identifying short-time, high frequency transients, as well as low frequency behavior over longer periods of time. In both cases the signals are non- periodic or non-stationary [6]. The fault transients of the study cases are analyzed through discrete wavelet transform at levels one to five. Both approximation and details information related fault current are extracted from the original signal with the multi-resolution analysis.

\section{FAULT DETECTION, CLASSIFICATION AND LOCATION}

Fault classification identifies the type of fault on the fault lines in the system. There are different methods proposed for the fault classification. This section reviews wavelet based method. The wavelet based approach for fault classification is implemented using multi resolution analysis (MRA) of voltage and current signals [7]. MRA is the process of decomposing a signal into different levels of resolutions [1]. Initially, the signal is passed through two discrete wavelet transform (DWT) filters - high pass (HP) filter and low pass (LP) filter. The samples of output signal from the HP filter are known as detail coefficients, and those from the LP filter are known as approximated coefficients. This is considered the first level. Next, the obtained samples from LP filter (first level approximated coefficients) are further processed through HP and LP filters forming the second level. In this way, the original signal can be processed through many levels depending on the need of resolution of signal. Once fault classification is completed, the next step is to determine the fault location. The fault location identifies the position of fault in the power system. There is different method of fault location; however in this paper travelling wave theory method is implemented. The travelling wave theory based method uses the information of voltage and current travelling waves for locating the fault. At the point of fault location, voltage and current waveforms get suddenly disturbed. Such disturbance causes them to propagate through the power system. Based on the total length of the faulted line. Propagation velocity and time of waveforms, the location of fault is known. This technique is mostly used for extra high voltage transmission lines than distribution lines because distribution system contains many subsections such as laterals and feeders. These subsections may create disturbances for the travelling waves on the lines. Reference [7] explains fault location technique based on the traveling wave theory. It includes two methods - the single ended method and the double ended method. In the single ended method, only one fault locator is installed at one substation. Depending on the arrival time of waves at that substation, the location of the fault is estimated. In double ended method, there are two fault locators installed at two substations and depending on the arrival time of waves at both stations, the fault location is calculated

\section{SCHEME OF EVALUATION OF PRAPOSED SYSTEM}

In this paper travelling wave based approach is followed and performing the comparison of the transient signals at all phases in power cable model, the classification of fault can be made. If the transient signal appears at only one phase then the fault is single line to ground fault. In general, the generated transient signals caused due to the fault is found to be non-stationary and is of wide band of frequency, when fault occurs in the network, the generated transient signals travels in the network. On the arrival at a discontinuity position, the transient wave is in general reflected partly and the remainder is incident to the line impedance. The transient signals reflected from the end of the line travels back to the fault point where another reflection takes place due to the discontinuity of impedance. Here in this fault identification and localization scheme, in order to capture these transient signals the wavelet analysis approaches have been employed more precisely for wavelet analysis. 
The fault location can be carried out by comparing the aerial mode wavelet coefficient to determine the time instant when the energy of the signal reaches its peak value. The distance between the fault point and the bus of the faulted branch is in general stated by the following equation (6).

$$
x_{2}=x-\frac{\left(\mathrm{t}_{1}-\mathrm{t}_{2}\right) v}{2}
$$

Where D represents the distance to the fault $t_{d}$ refers for the time difference between two consecutive peaks of the wavelet transform coefficients of the recorded current and $v$ is the wave propagation velocity in the aerial mode. An

underground cable of length $50 \mathrm{~km}$ has been employed for fault analysis. The travelling wave velocity of the signals in

the $11 \mathrm{kV}$ underground cable system is $1.9557 \times 10 \mathrm{~km} / \mathrm{s}$, and sampling time of $10 \mu \mathrm{s}$ has been employed. The following figure represents the single line diagram of the simulated system with $11 \mathrm{kv}, 50 \mathrm{~Hz}, 10 \mathrm{~km}$ underground cable. To perform the system analysis, varied fault conditions such as LG, LLG and LLLG faults have been considered and associated detection parameters have been obtained. The performance has been evaluated in terms of $\%$ error and the deviation from the actual values. The overall process of fault detection and location has been accomplished. Consider a

three phase cable line of length $\mathrm{X}$ connected between bus A and bus B, with characteristic impedance $Z_{c}$ and travelling wave velocity of $v$. In this simulation model it has been found that if a fault occurs at a distance $x_{2}$ from bus $A$, this will appear as an abrupt injection at the fault point. This injection will travel like a wave "surge" along the line in both

directions and will continue to bounce back and forth between fault point, and the two terminal buses until the post- fault steady state is reached. The distance to the fault point can be calculated $b_{u}$ using travelling wave theory. Let $t_{1}$ and $t_{2}$ corresponds to the times at which the modal signals wavelet coefficients in scale1, show their initial peaks for signals recorder at bus $\mathrm{A}$ and bus $\mathrm{B}$. the delay between the fault detection times at the two ends is $t_{1}-t_{2}$ can be determined. Once the parameter $t_{d}$ is determined, the fault location from bus A can be estimated as per the following expression (3).

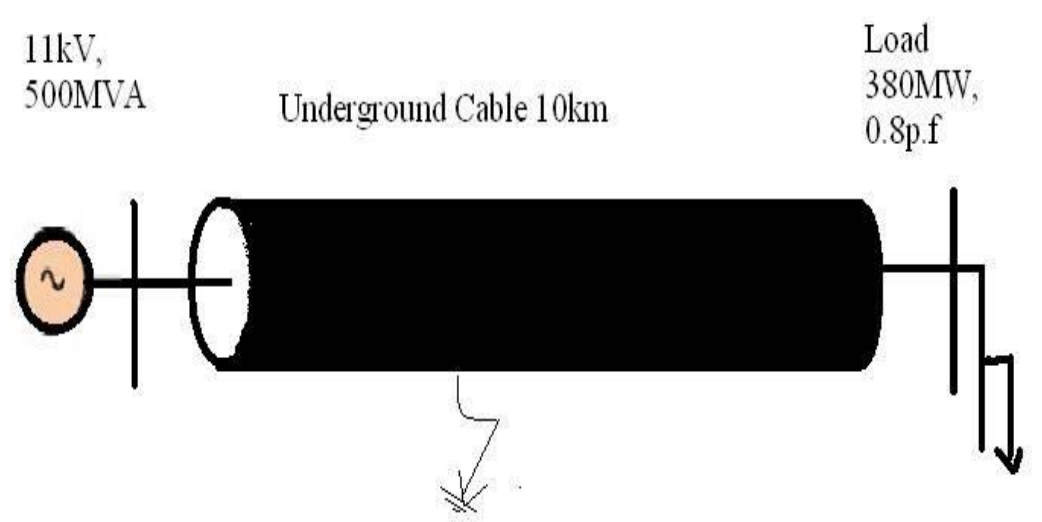

Figure 1.Single line diagram of the proposed system

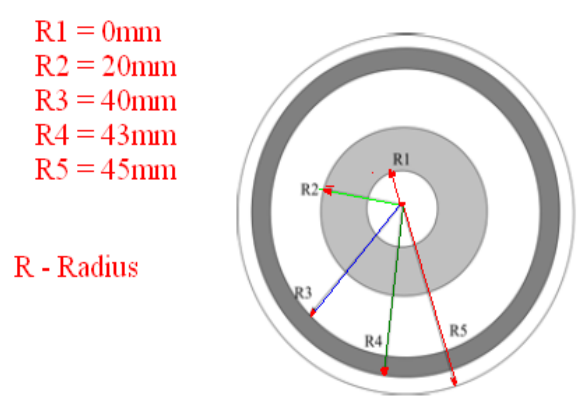

Figure2. Configuration of underground cable 


$$
x_{2}=x-\frac{\left(\mathrm{t}_{1}-\mathrm{t}_{2}\right) v}{2}
$$

Or the fault location can be calculated from bus B as follows expression (8)

$$
x_{1}=x-\frac{\left(\mathrm{t}_{2}-\mathrm{t}_{1}\right) v}{2}
$$

The travelling wave velocity can be obtained from the equation as follows (9)

$$
v=\frac{3 \times 10^{8}}{\sqrt{\varepsilon r \mu r}} \mathrm{~m} / \mathrm{s}
$$

Here the travelling wave velocity, $v$ shown in equation (9) is assumed to be $1.9557 \times 10^{5} \mathrm{~km} / \mathrm{s}$, with sampling time of 10 us and the total line length $10 \mathrm{~km}$. in the above mathematical model the variable $\mathrm{X}_{1}$ and $\mathrm{X}_{2}$ represents the distance to the fault, $t_{d}$ is the time difference between two consecutive peaks of the wavelet transforms coefficients of the recorded current and $v$ is the wave propagation velocity.

\section{RESULT AND DISCUSSION}

The parameters of the proposed system are as follows Source: $V_{L}=11 \mathrm{kV}, \mathrm{f}=50 \mathrm{~Hz}, \mathrm{Xs}: \mathrm{Rs}=10$, $\mathrm{Xs}=2 \Omega$, Rs $=0.2 \Omega$ Cables: XLPE, Three-phase cable, Transformer: $S=1$ MVA Winding 1 : $\mathrm{V}_{\mathrm{L}}=11 \mathrm{kV}, \mathrm{Rp}=1 \Omega, \mathrm{Lp}=28.6 \mathrm{mH}$ Winding $2: \mathrm{V}_{\mathrm{L}}=380 \mathrm{~V}, \mathrm{Rs}=0.00044 \Omega, \mathrm{Ls}=0.0114 \mathrm{mH}$ Load 1 : Three-phase static Load: VL=380 Vrms, $\mathrm{f}=50 \mathrm{~Hz}, \mathrm{PL}=92.62 \mathrm{~kW}, \mathrm{QL}=69.252 \mathrm{kVAR}$ Load 2: The combination of a three $=$ phase static and dynamic loads Dynamic Load: VL $=380 \mathrm{Vrms}, \mathrm{f}=50 \mathrm{~Hz}$, $\mathrm{P}=200$ HP, Static Load: PL=92.62kW, QL=69.252kVAR, VL $=380$ Vrms Load 3: Three-phase static Load: $\mathrm{VL}_{\mathrm{L}}=11 \mathrm{kVrms}, \mathrm{f}=50 \mathrm{~Hz}, \mathrm{PL}=124 \mathrm{~kW}, \mathrm{QL}=952 \mathrm{kVAR}$. From the simulation results it was observed that, under normal working condition the maximum current is $0.96 \mathrm{kA}$, however due to faults it is $1.789 \mathrm{kA}(\mathrm{Lg}), 1.8255 \mathrm{kA}(\mathrm{LLg})$ and

$2.212 \mathrm{kA}$ (LLLg) respectively. Similarly from the results it was observed that the first peak time is at $\mathrm{t}_{1}=0.04002$ at a peak of 79257 and $\mathrm{t}_{2}=0.040189$ at a peak value of 142472 . The figure $2 \mathrm{a}$ shows the overall flowchart of the proposed algorithm for detection, classification and location of the fault of the proposed system.

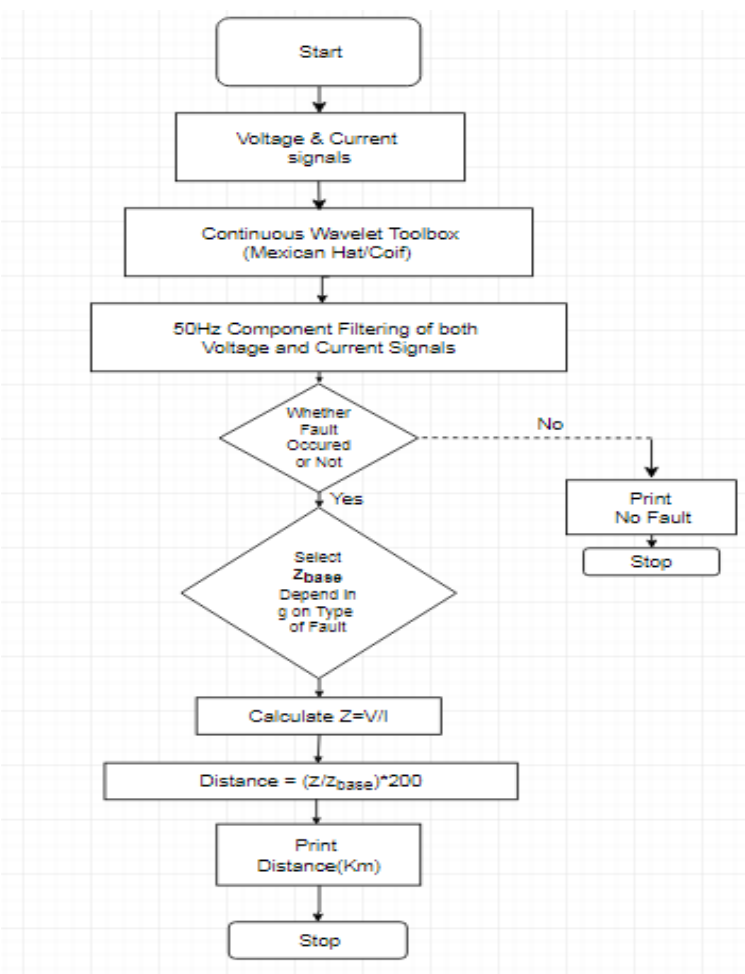

Fig.2a.The overall flowchart of the proposed algorithm 
In the fig 2.It shows the grapg of three phase current Vs time and from the graph it can be observed that. three phase sinusoidal wave form is undistorted and it indicates that the system is running under normal conditions without any faults.

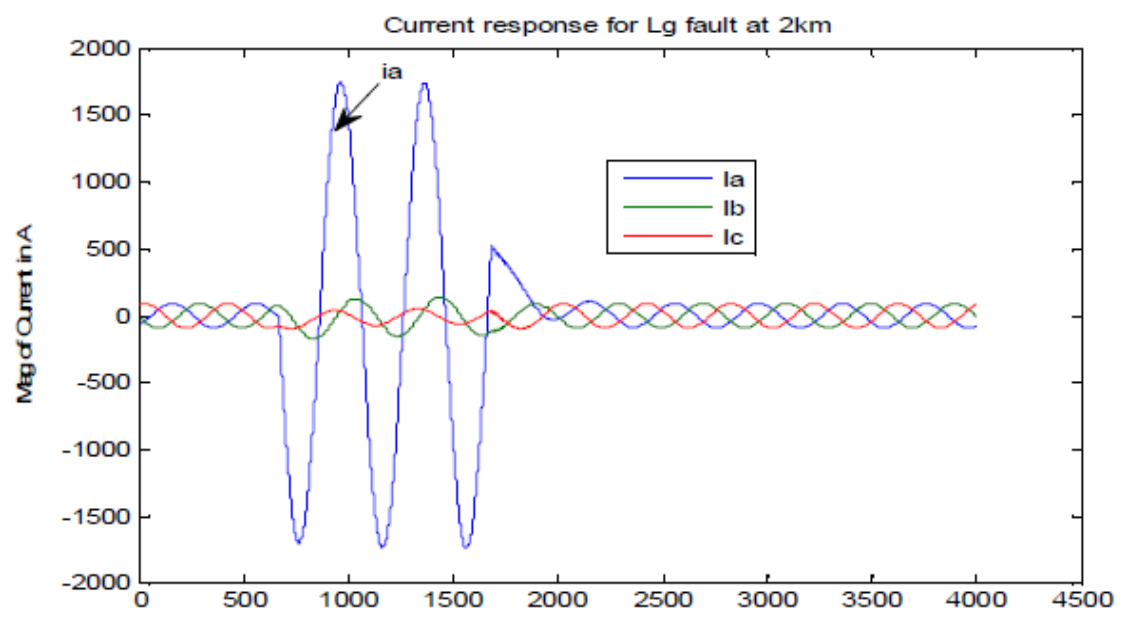

Fig3. Current response for $\mathrm{Lg}$ fault at $2 \mathrm{~km}$

In the fig 3, it shows the graph of fault curent Vs time and from the figure it can be obseved that there is a single line to ground fault and rise of fault current level of more than $1.5 \mathrm{kA}$.

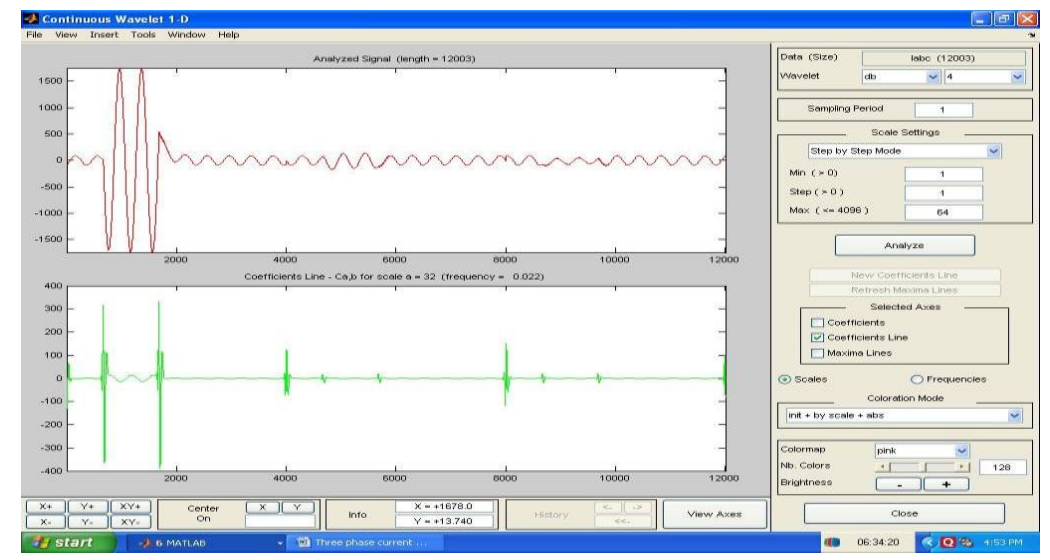

Fig4. Current response for $\mathrm{Lg}$ fault at $2 \mathrm{~km}$ by wavelet $\mathrm{Db4}$

In fig 4. It show that fault current with wavelet transform (Db4) for single line to ground fault in at level 4.

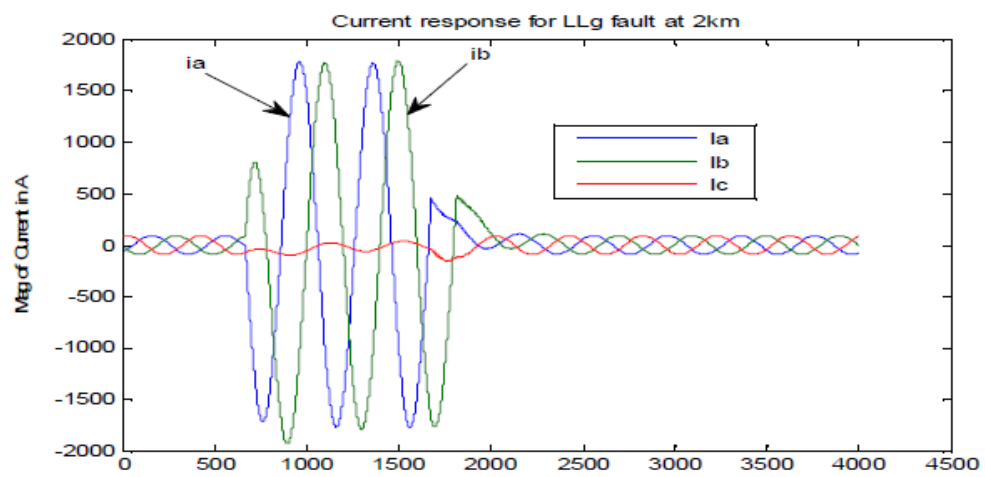

Fig5. Current response for $\mathrm{LLg}$ fault at $2 \mathrm{~km}$

In the fig 3, it shows the graph of fault curent Vs time and from the figure it can be obseved that there is a double line to ground fault and rise of fault current level of more than $1.8 \mathrm{kA}$. 


\section{FAULT DETECTION IN UNDERGROUNDCABLES BY USING WAVELET TECHNIQUE (WT)}

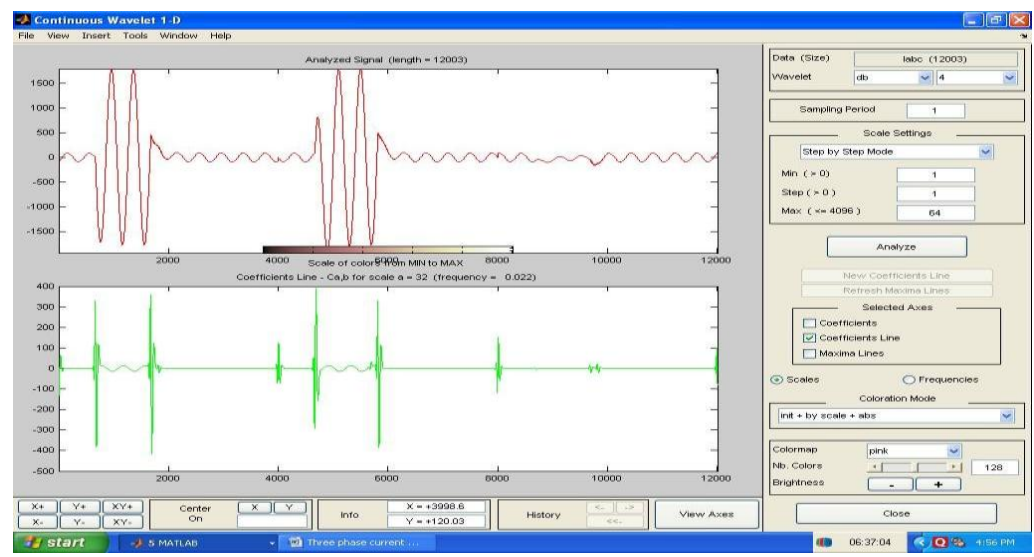

Fig6. Current response for $\mathrm{LLg}$ fault at $2 \mathrm{~km}$ by wavelet Db4

In fig 6. It show that fault current with wavelet transform (Db4) for double line to ground fault in at level 4.

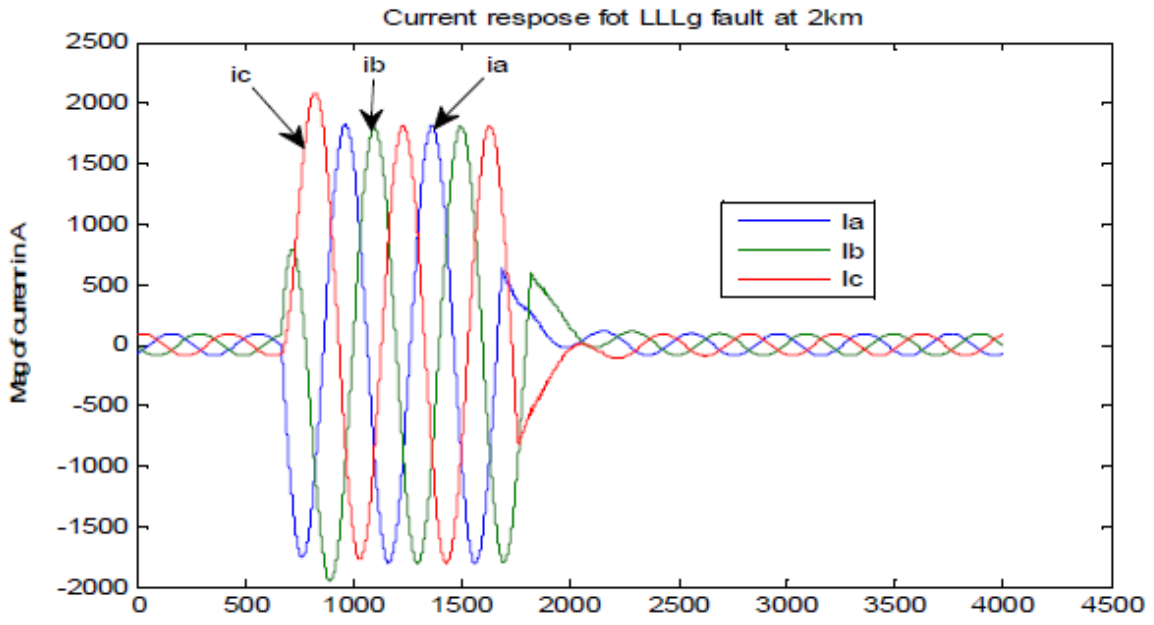

Fig7. Current response for LLLg fault at $2 \mathrm{~km}$

In the fig 7 , it snows tne grapn or rauıt curent vs tıme ana Irom tne IIgure it can pe obsevea tnat tnere is a triple line to ground fault and rise of fault current level of more than $2 \mathrm{kA}$.

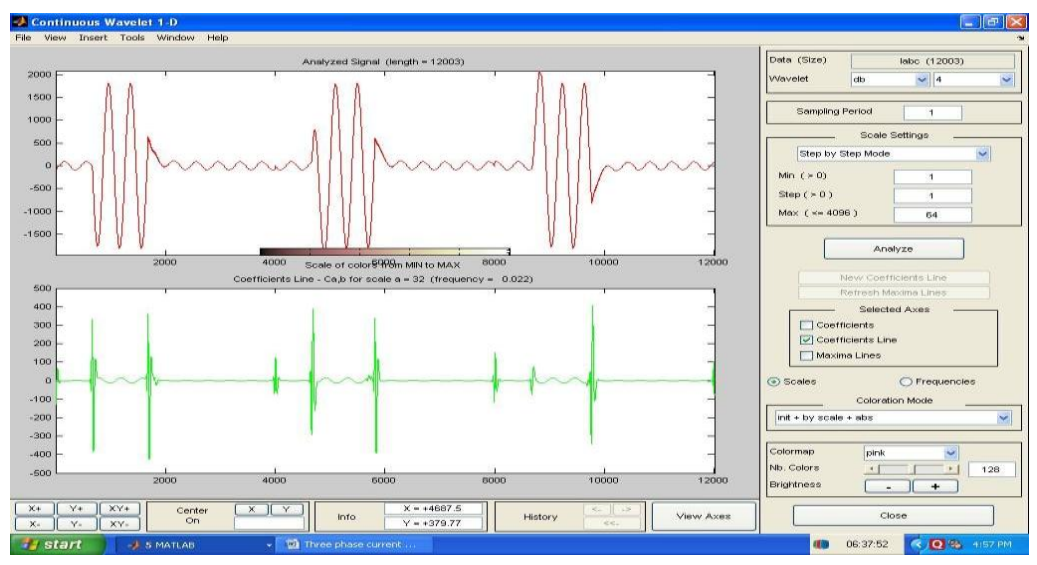

Fig8. Current response for LLLg fault at $2 \mathrm{~km}$ by wavelet

Db4

In fig 8. It show that fault current with wavelet transform (Db4) for triple line to ground fault in at level 4. 


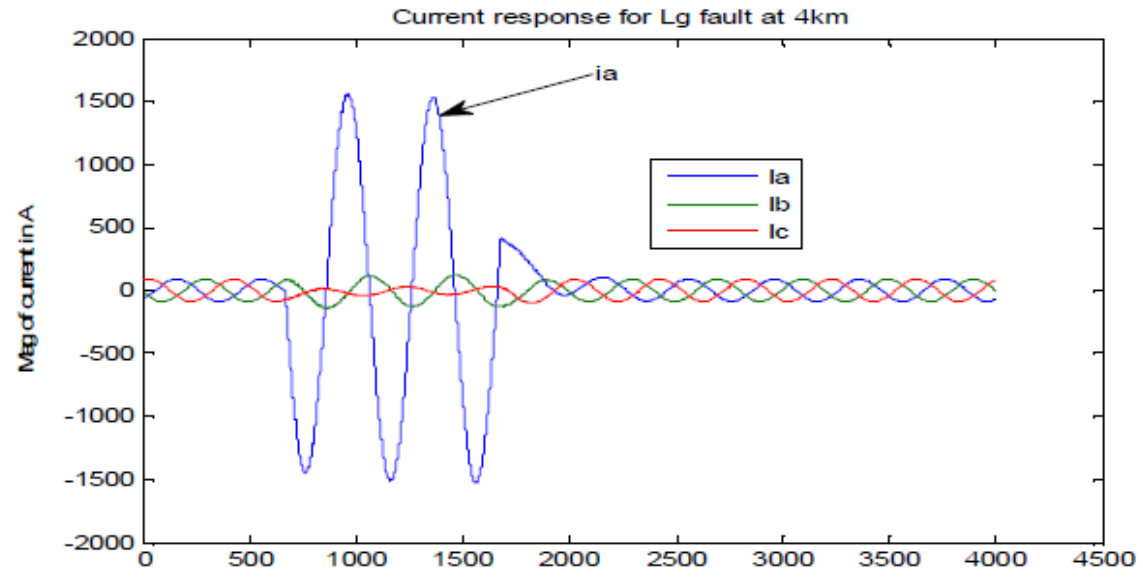

Fig 9. Current response for $\mathrm{Lg}$ fault at $4 \mathrm{~km}$

In the fig 7, it shows the graph of fault curent Vs time and from the figure it can be obseved that there is a single line to ground fault and rise of fault current level of more than $1.5 \mathrm{kA}$ but it is somewhat less than for fault at $2 \mathrm{~km}$. (IfLg for $4 \mathrm{~km}<\mathrm{g}$ of $2 \mathrm{~km}$ ).

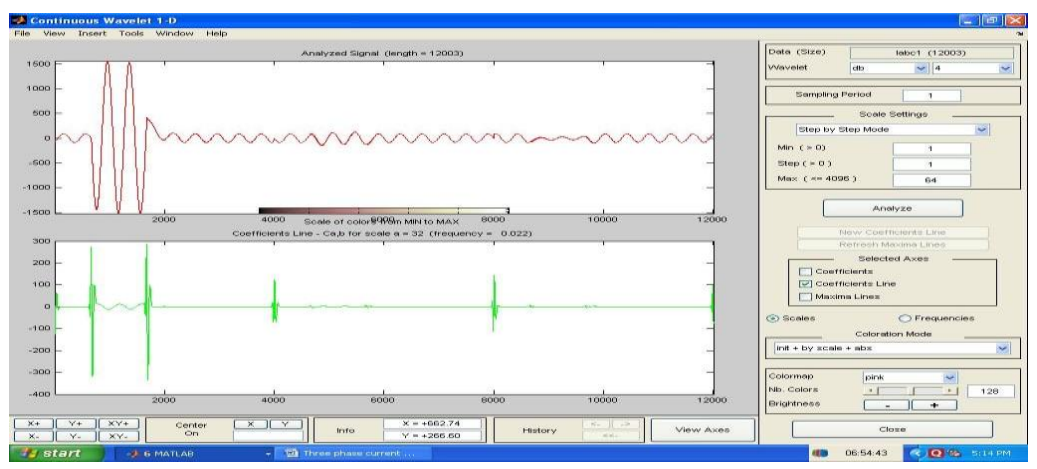

Fig 10. Current response for $\mathrm{Lg}$ fault at $4 \mathrm{~km}$ by wavelet $\mathrm{Db} 4$

In fig 10. It show that fault current with wavelet transform (Db4) for single line to ground fault in at level 4. 


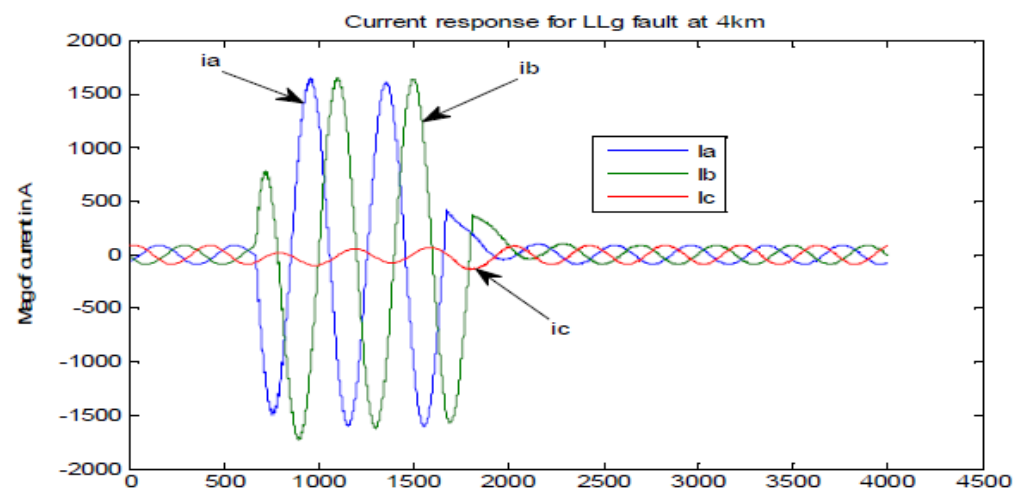

Fig11. Current response for $\operatorname{LLg}$ fault at $4 \mathrm{~km}$

In the fig 11, it shows the graph of fault curent Vs time and from the figure it can be obseved that there is a double line to ground fault and rise of fault current level of more than $1.5 \mathrm{kA}$ but it is less than that of magnitude of fault current for single line to ground fault of lenghth $2 \mathrm{~km}$.(IfLLg of $4 \mathrm{~km}$ or $\mathrm{f} 4 \mathrm{~km}<\mathrm{IfLg}$ of $2 \mathrm{~km}$ )

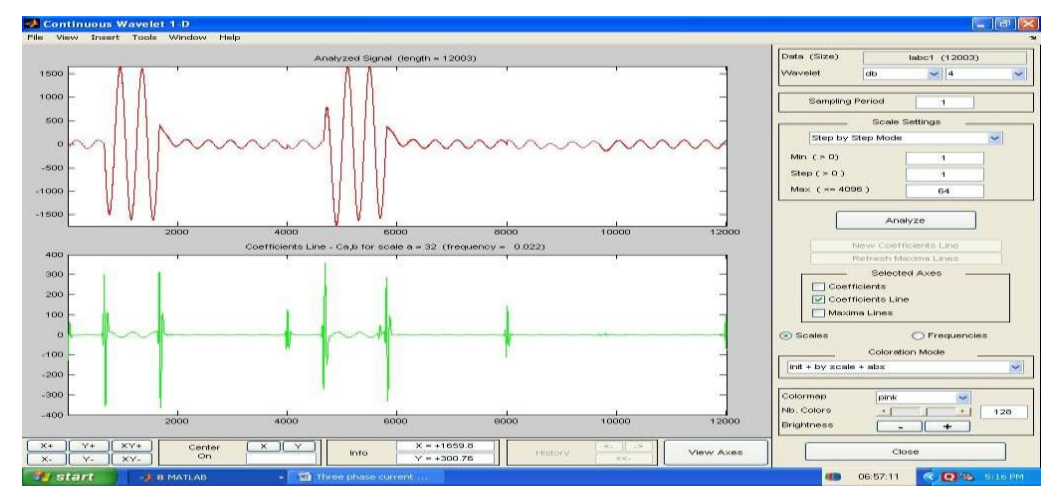

Fig12. Current response for LLg fault at $4 \mathrm{~km}$ by wavelet $\mathrm{Db} 4$

In fig 12. It show that fault current with wavelet transform (Db4) for double line to ground fault in at level 4.

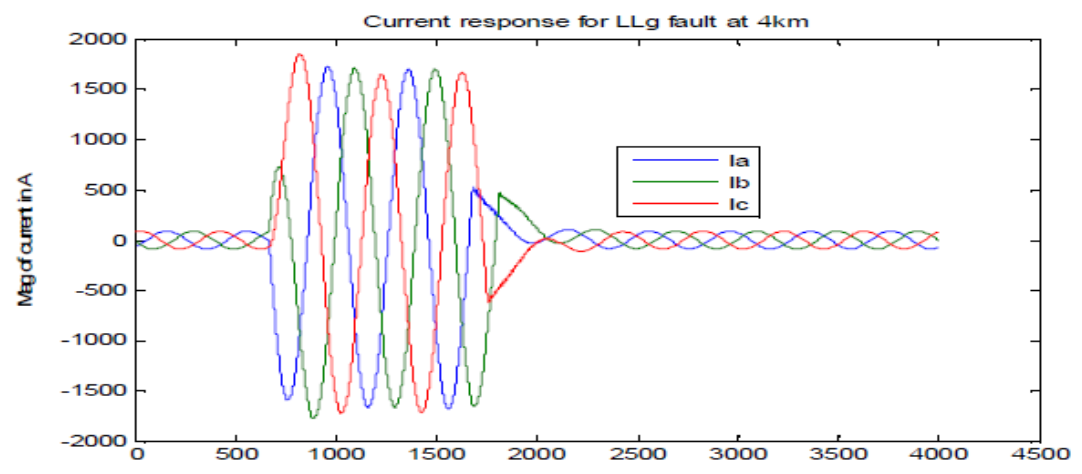

Fig 13. Current response for LLLg fault at $4 \mathrm{~km}$

In the fig 13, it shows the graph of fault curent Vs time and from the figure it can be obseved that there is a triple line to ground fault and rise of fault current level of more than $1.5 \mathrm{kA}$ but it is less than that of magnitude of fault current for triple line to ground fault of $2 \mathrm{~km}$ length (If LLLg of $4 \mathrm{~km}<$ IFLLg of $2 \mathrm{~km}$ ) 


\section{FAULT DETECTION IN UNDERGROUNDCABLES BY USING WAVELET TECHNIQUE (WT)}

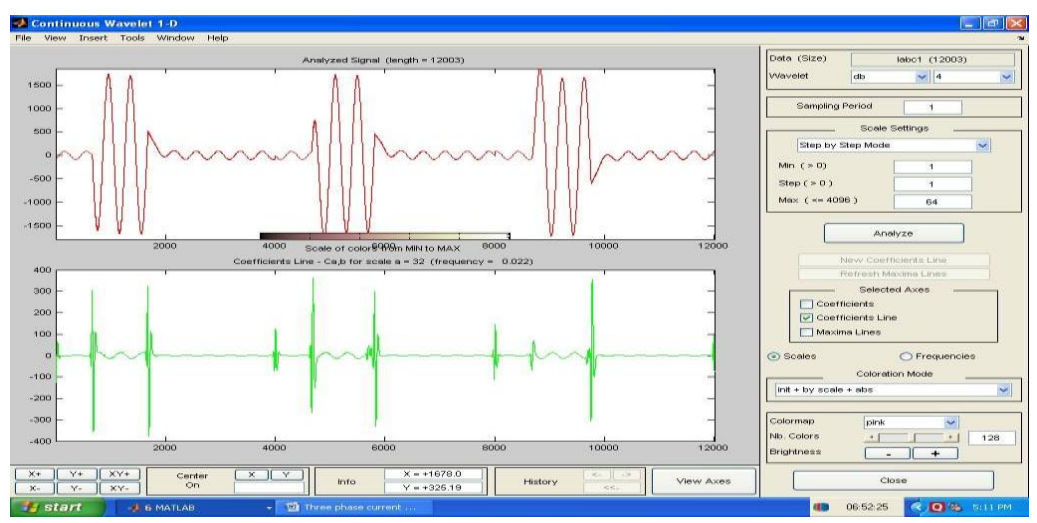

Fig 14. Current response for LLLg fault at $4 \mathrm{~km}$ by wavelet Db4

In fig 12. It show that fault current with wavelet transform (Db4) for triple line to ground fault in at level 4.

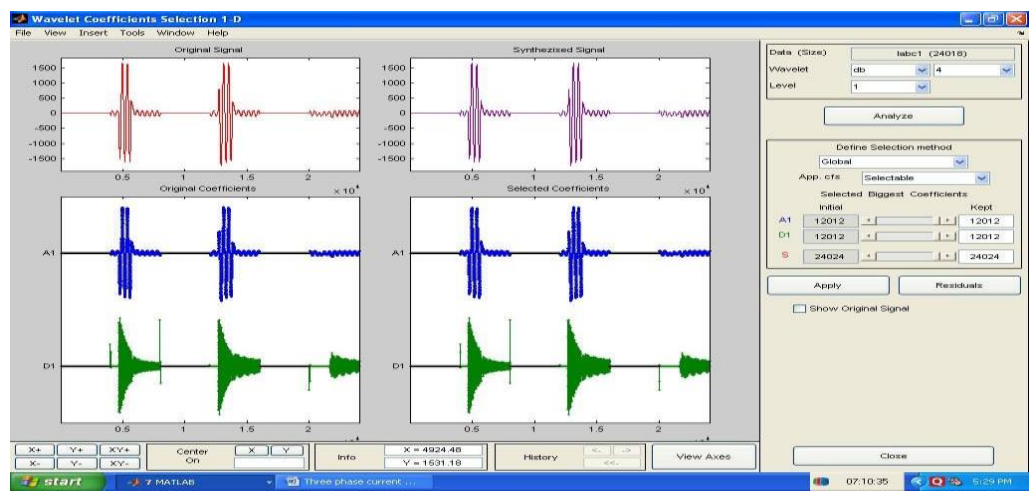

Fig 15.Wavelet coefficients of level 5

In fig 15. It shows the original single and sythezised signals in the range of -1500 to +1500 along with original coefficients and selected coefficients $D_{1} D_{2} D_{3} D_{4} D_{5} A_{5}$ level 5 .

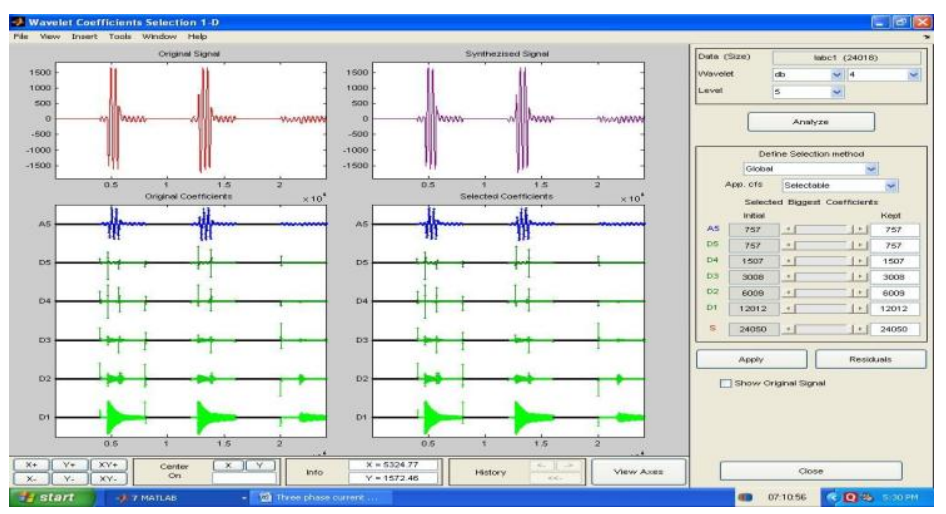

Fig16.Wavelet coefficients of level 1

In fig 16. It show the original single and sythezised signals in the range of -1500 to +1500 along with original coefficients and selected coefficients $D_{1} D_{2} D_{3} D_{4} D_{5} A_{5}$ at level 1 .

Table1. Percentage of error calculated by Impedance method

\begin{tabular}{|c|c|c|}
\hline Actual Distance $(\mathrm{Km})$ & Calculated Distance $(\mathrm{Km})$ & \% Error $(\mathrm{Km})$ \\
\hline 2 & 2.29 & 2.9 \\
\hline 4 & 4.51 & 5.1 \\
\hline 6 & 6.32 & 3.2 \\
\hline
\end{tabular}


Table2. Percentage of error for single line to ground fault at different locations

\begin{tabular}{|c|c|c|c|c|}
\hline $\begin{array}{c}\text { Actual Distance } \\
(\mathrm{Km})\end{array}$ & \multicolumn{2}{|c|}{$\begin{array}{c}\text { First Peak Time } \\
(\mathrm{ms})\end{array}$} & \multicolumn{2}{c|}{$\begin{array}{c}\text { Proposed Technique } \\
(\mathrm{Db} 4)(\mathrm{Km})\end{array}$} \\
\hline & $\mathrm{t}_{1}(\mathrm{~ms})$ & $\mathrm{t}_{2}(\mathrm{~ms})$ & Calculated $(\mathrm{km})$ & Error $(\mathrm{Km})$ \\
\hline 2 & 0.042 & 0.049 & 2.219 & 0.129 \\
\hline 4 & 0.0405 & 0.04013 & 4.136 & 0.136 \\
\hline 6 & 0.0407 & 0.04015 & 6.198 & 0.196 \\
\hline
\end{tabular}

\section{CONCLUSION}

In this paper at first, a new method to analyze power distribution system transient signals basedMatLab version 7.8 is proposed by using WT technique. This method offers important advantages over other methods such as FFT and STFT due to good time and frequency localization characteristics. Analysis results presented clearly show that particular wavelet components can be used as the features to locate the fault in underground cables in distribution system.

This Study shows that the scheme is insensitive to fault type, and fault position on the cable. Studies also show that the wavelet technique is able to offer a very high accuracy in fault detection and fault location on underground cable. The simulation work carried for different faults single line to ground ( $\mathrm{Lg}$ ). Double line to ground (LLg) and three phase to ground( LLLg) at different points $2 \mathrm{~km}, 4 \mathrm{~km}$ and $6 \mathrm{~km}$ from the source end and the simulation results are shown in figures from 2 to figure 14, figure 15 and 16 shows the wavelet coefficients for level1 and 5. As a result, the application of the discrete wavelet transform (DWT) based on traveling wave is a good choice to detect the fault in underground power cable.

\section{REFERENCES}

1. Chul-Hwan, Hyun km and Young, "A novel fault-detection technique of high-impedance arcing faults in transmission lines using the wavelet transform." IEEE Power Engineering http://ieeexplore.ieee.org/browse/periodicals/title/ pp. 921-929. 2002.

2. J.Moshtagh and R.K.Aggarwal, "A new approach to fault location in a single core underground cable system using combined fuzzy logic and wavelet analysis," Power Delivery, IEEE Transactions on, vol. 15, pp. 228- 231, 2004.

3. ALI Rafinia,Jamal Moshtaagh" A new approach to fault location in three-phase underground distribution system using combination of wavelet analysis with ANN and FLS ' Volume 55,PP 261-274,2014

4 .IEEE Transmission and Distribution Conference, Yokohama, Japan, pp. 2246-2250. October 2002.A. Ferrero, S. Sangiovanni and E. Zappitelli, "A Fuzzy-set approach to fault-type identification in digital relaying," IEEE Transaction on Power Delivery, Vol. 10, No. 1, pp. 169175. January 1995.

5. Ibrahem baqui, Inmaculade Zamara, Javier mazan, garikoitz buigues. "High impedance fault detection methodology using wavelet transform and artificial neural networks ", Volume 81, Issue 7, July 2011, Pages 1325-1333

6. C.K. Jung, J.B. Lee, X.H. Wang, Y.H. Song "Wavelet based noise cancellation technique for fault location on underground power cables" EPSR, 77, pp. 1349-1362, 2007.

7. C. Apisit and A. Ngaopitakkul, "Identification of Fault Types for Underground Cable using Discrete Wavelet transform" Proceedings of The International MultiConference of Engineers and Computer Scientists 2010, pp.1262-1266, 